INFLAMMATORY BOWEL DISEASE

\title{
Antibiotics with a selective aerobic or anaerobic spectrum have different therapeutic activities in various regions of the colon in interleukin 10 gene deficient mice
}

\author{
F Hoentien, H J M Harmsen, H Braat, C D Torrice, B A Mann, R B Sartor, L A Dieleman
}

Gut 2003;52:1721-1727

See end of article for authors' affiliations

Correspondence to:

Correspondence to:
Dr F Hoentjen, Department of Medicine, Division of Digestive Diseases, Biomolecular Research Building, Rm 7331, CB 7032, UNC-Chapel Hill, Chapel Hill, NC 275997032, USA: frank_hoentjen@ med.unc.edu

Accepted for publication 24 July 2003

\begin{abstract}
Background and aims: Multiple rodent models implicate resident intestinal bacteria in the pathogenesis of chronic immune mediated intestinal inflammation. Specific pathogen free (SPF) interleukin 10 gene deficient (IL-10 $\left.10^{-/}\right)$mice develop colitis, which does not occur in the germ free (GF) state. We investigated whether broad or narrow spectrum antibiotics affect onset and progression of disease in various regions of IL-10-1- mice.

Methods: Metronidazole, ciprofloxacin, vancomycin-imipenem $(50 \mathrm{mg} / \mathrm{kg} /$ day), or water (control) was administered orally before (prevention) or two weeks after (treatment) colonisation of GF IL-10 $0^{-1-}$ mice with SPF bacteria. After four weeks, colonic histology scores and cytokine production by colonic explants were determined. Caecal and colonic contents were collected for quantitative bacterial analysis.

Results: In the prevention study, all antibiotics decreased inflammation in the caecum and colon. However, in the treatment study, ciprofloxacin and vancomycin-imipenem decreased caecal inflammation, and reduced Escherichia coli and Enterococcus faecalis concentrations, whereas only vancomycin-imipenem lowered direct microscopic bacterial counts. In contrast, metronidazole and vancomycin-imipenem reduced colonic injury and eliminated anaerobic bacteria, including Bacteroides spp.

Conclusions: Both narrow and broad spectrum antibiotics can prevent disease but treatment of established colitis is more selective. Ciprofloxacin is most effective in the treatment of caecal inflammation, metronidazole preferentially treats the colon, whereas vancomycin-imipenem definitively treats both regions. These results suggest that subsets of aerobic or anaerobic bacteria show regional differences in their capacity to mediate experimental colitis in $\mathrm{IL}-10^{-/-}$mice.
\end{abstract}

n recent years, multiple studies have emphasised the role of commensal intestinal bacteria in the pathogenesis of inflammatory bowel diseases (IBD). ${ }^{12}$ In several genetically engineered and induced rodent models of chronic immune mediated intestinal inflammation, susceptible hosts develop spontaneous colitis in the presence of non-pathogenic resident intestinal bacteria, which does not occur in the germ free $(\mathrm{GF})$ state. $^{3}$

In a well characterised murine model of $\mathrm{T}$ helper $\mathrm{l}$ (THI) mediated colitis, interleukin 10 gene deficient (IL-10 $10^{-/-}$) mice develop predominantly caecal inflammation shortly after weaning when susceptible strains (129 SvEv or mixed $129 / \mathrm{C} 57 \mathrm{Bl} / 6$ background) are colonised with specific pathogen free (SPF) bacteria. ${ }^{4}$. As disease progresses, inflammation also develops in the ascending and transverse colon, and finally in the remainder of the colon and rectum. ${ }^{45}$. In contrast, GF conditions prevent development of inflammation in this model, emphasising the essential role of commensal intestinal organisms in the pathogenesis of chronic intestinal inflammation. ${ }^{5}$ These observations are consistent with results in other models of chronic intestinal inflammation, such as in HLA-B27/ $\beta 2$ microglobulin transgenic (TG) rats, IL-2 $2^{-1-}$, TCR $\alpha^{-1-}$, SAMP-1/Yit, and $\mathrm{CD} 3 \epsilon_{26}$ TG mice in which the GF state prevents disease development and immune activation. ${ }^{6-12}$ The role of intestinal bacteria in the pathogenesis of experimental colitis was further emphasised after showing that broad spectrum antibiotics can both prevent and treat colitis in HLA-B27 TG rats and dextran sulphate sodium (DSS) induced colitis in BALB/C mice, ${ }^{13}$ as well as in IL- $10^{-/-}$mice. $^{14}$

However, it is relatively unknown how different subsets of aerobic or anaerobic bacteria influence the onset and perpetuation of experimental colitis. We describe a study in gnotobiotic IL- $10^{-1-}$ mice which were colonised with SPF bacteria that had the following objectives: (1) investigate whether narrow spectrum antibiotics affect onset and progression of colitis, (2) explore regional differences in the prevention and treatment of colonic and caecal inflammation by antibiotic administration and (3) correlate the therapeutic effects of narrow spectrum antibiotic treatment with the composition of intestinal aerobic and anaerobic bacteria.

\section{MATERIALS AND METHODS}

Mice

GF IL- $10^{-1-}$ mice (C57BL/6 $\times 129 /$ Ola mixed background) were originally derived at the University of Wisconsin (Gnotobiotic Laboratory, Madison, Wisconsin, USA) and bred at the gnotobiotic Rodent Care Facility of the Center for Gastrointestinal Biology and Disease at the College of Veterinary Medicine (North Carolina State University, Raleigh, North Carolina, USA).

\section{Experimental design}

Two to five months old IL- $10^{-1-}$ mice raised under GF conditions were transferred to SPF conditions where bedding

Abbreviations: CFU, colony forming units; FISH, fluorescent in situ hybridisation; GF, germ free; IBD, inflammatory bowel diseases; IL, interleukin: IL-10 $0^{-1-}$, interleukin 10 gene deficient; MLN, mesenteric lymph node; SPF, specific pathogen free; TG, transgenic; TH1, Thelper 1 ; DSS, dextran sulphate sodium; PBS, phosphate buffered saline; DAPI, diamidino-2-phenylindole 
from Helicobacter species free SPF mice was added to each cage. The mice were colonised with Helicobacter species free SPF bacteria by oral and rectal swabbing with a slurry of freshly passed faeces, as described previously. ${ }^{5}{ }^{15}$

In the prevention study, metronidazole, ciprofloxacin, or a combination of vancomycin and imipenem was administered in the drinking water at $50 \mathrm{mg} / \mathrm{kg}$ body weight/day starting at the time of SPF bacterial colonisation; control mice received only water. Each group consisted of 4-5 mice. After four weeks, mice were killed and the caecum and various parts of the colon were collected for histology and colonic explants cultures.

In the treatment study, gnotobiotic IL- $10^{-/-}$mice did not receive any treatment for two weeks after colonisation with SPF faecal bacteria. Subsequently, metronidazole, ciprofloxacin, or vancomycin-imipenem was administered in the drinking water at $50 \mathrm{mg} / \mathrm{kg}$ body weight/day; control mice received only water. Each treatment group consisted of 4-5 mice. At four weeks after the start of antibiotic treatment, mice were killed and the caecum and colon were collected for histology and colonic explants cultures. Caecal and colonic contents were obtained for quantitative bacteriology and fluorescent in situ hybridisation (FISH), as described below. All studies were approved by the University of North Carolina at Chapel Hill Institutional Animal Care and Use Committee.

\section{Histology}

At necropsy, transverse and longitudinal sections of the caecum and proximal, transverse, and distal parts of the colon were obtained and prepared as previously described. ${ }^{5}{ }^{15}$ Briefly, tissues were fixed in $10 \%$ formalin, embedded in paraffin, and stained with haematoxylin and eosin. A validated histological inflammatory score ranging from 0 to 4 was used for blinded evaluation, based on the degree of cellular infiltration, crypt hyperplasia, goblet cell depletion, and architectural distortion. ${ }^{5} 15$

\section{Colonic tissue fragment cultures}

Cultures of colonic fragments were prepared following published methods, ${ }^{16}$ as described previously. ${ }^{5}$ Caecal fragments were not studied because the amounts of available caecal tissue were too small. Briefly, colonic tissue was fragmented and the precise weight per well was determined, which was always in the $50-100 \mathrm{mg}$ range. Colonic tissue was cultured at $37^{\circ} \mathrm{C}$ in $1 \mathrm{ml}$ of complete RPMI medium, as described previously, ${ }^{5}$ and supernatants were collected after 18 hours and stored at $-20^{\circ} \mathrm{C}$ until assay. IL- $1 \beta$ and IL- 12 production were measured and the results were normalised for the exact tissue weight used per well. Under these conditions autolysis of colonic fragments, especially epithelial cells, is expected. However, autolysis is expected to be consistent in all treatment groups, and therefore should not affect the outcome.

\section{Cytokine measurements}

We used commercially available antimouse IL-1 $\beta$ and IL-12 reagents (BD Pharmingen, San Diego, California, USA) in validated ELISA protocols to measure amounts of IL- $1 \beta$ and IL-12 in the colonic culture supernatants. ${ }^{5}{ }^{15}$ Cytokine levels were measured in duplicate and compared with standard curves using recombinant murine cytokines.

\section{Quantitative bacteriology of caecal and colonic luminal content}

Caecal and colonic contents were collected and serially diluted at 10 -fold dilutions in $1 \times$ PBS. For aerobic culture, the diluted contents were plated and cultured at $37^{\circ} \mathrm{C}$ for 24 hours on sheep blood agar (total aerobes), Mac Conkey (Escherichia coli), and bile esculin with azide (enterococci) agar plates. For anaerobic cultures, caecal and colonic contents were plated within one hour on BHI (total anaerobes) or Bacteroides bile esculin agar plates in anaerobic Gas Pak jars (BBL, Cockeysville, Maryland, USA) at $37^{\circ} \mathrm{C}$ for 48 hours. Bacterial colonies were counted, identification of specific organisms was performed by Gram staining, biochemical characterisation using standard biochemical tests, and confirmed by FISH, as described below. Direct microscopic bacterial counts of caecal and colonic content were assessed using a Petroffhauser counting chamber prior to bacterial culture, therefore providing an independent method of determining bacterial concentrations to complement the bacterial culture results.

\section{Fluorescent in situ hybridisation}

An accurately weighed portion of approximately $100 \mathrm{mg}$ of caecal or colonic luminal content was diluted 10 times with filtered $(0.2 \mu \mathrm{m}$ pore size) phosphate buffered saline (PBS). The diluted samples were homogenised by vortexing for three minutes with glass beads. Samples were diluted 1:3 with fresh $4 \%(\mathrm{w} / \mathrm{v})$ paraformaldehyde in PBS, fixed overnight at $4^{\circ} \mathrm{C}$, and then stored at $-80^{\circ} \mathrm{C}$ until required. Total hybridisable cell numbers were counted by diamidino-2phenylindole (DAPI) staining. ${ }^{17}$ Probe BAC303 was used for the detection of the Bacteroides/Prevotella genera. ${ }^{18}$ Probe EC1531 specific for $E$ coli and other Enterobacteriaceae was used to detect $E$ coli. ${ }^{19}$ The probe Lab158 was used to detect lactobacilli and enterococci. ${ }^{20}$ Enterococci were discriminated from lactobacilli using probe Efs, as described previously. ${ }^{20}$ Dilutions of the fixed samples in PBS were applied to slides with eight wells of $1 \mathrm{~cm} \times \mathrm{lcm} \quad(\mathrm{CBN}$, Drachten, the Netherlands). ${ }^{21}$ The slides were either hybridised with $100 \mu \mathrm{l}$ hybridisation buffer $(20 \mathrm{mM}$ Tris $\mathrm{HCl}, 0.9 \mathrm{M} \mathrm{NaCl}$, $0.1 \%$ sodium dodecyl sulphate, $\mathrm{pH} 7.2$ ) containing $5 \mathrm{ng} / \mu \mathrm{l}$ of one of the probes described above or stained with DAPI as described previously. ${ }^{17}$ The hybridisation assays were carried out overnight at $50^{\circ} \mathrm{C}$ in a dark humid chamber (three hours for the Bac303 and EC23S probes). After hybridisation, the slides were washed, air dried, and subsequently mounted with Vecta Shield (Vector Lab., Burlingame, California, USA). The fluorescent cells in the samples were counted automatically ${ }^{21}$ with a Leica DMRXA epifluorescence microscope (Leica, Wetzlar, Germany). However, when the cell number was lower than $4 \times 10^{8}$ cells/g wet weight, cells were counted visually using an Olympus BH2 epifluorescence microscope. All results are stated as bacterial count/g luminal content, thus normalised for the weight of luminal contents used during FISH analysis. Oligonucleotide probes were synthesised and purified by Eurogentec (Seraing, Belgium).

\section{Statistical analysis}

All data are expressed as mean (SEM). Data were analysed using the paired Student's $t$ test or the non-parametric Mann-Whitney test. Statistical significance was defined as $\mathrm{p}<0.05$ compared with mice from the water control group. The Spearman correlation coefficient was computed to measure the association between histology scores and bacterial counts, denoted by $r$. Positive values indicate a positive correlation, negative values a negative correlation, and a value of one indicates perfect correlation of the ranks. As several comparisons were made, $\mathrm{p}<0.01$ was considered statistically significant rather than the traditional value of 0.05 .

\section{RESULTS}

\section{Prevention study}

We first studied the ability of narrow and broad spectrum antibiotics to prevent onset of colitis in GF IL- $10^{-/-}$mice 

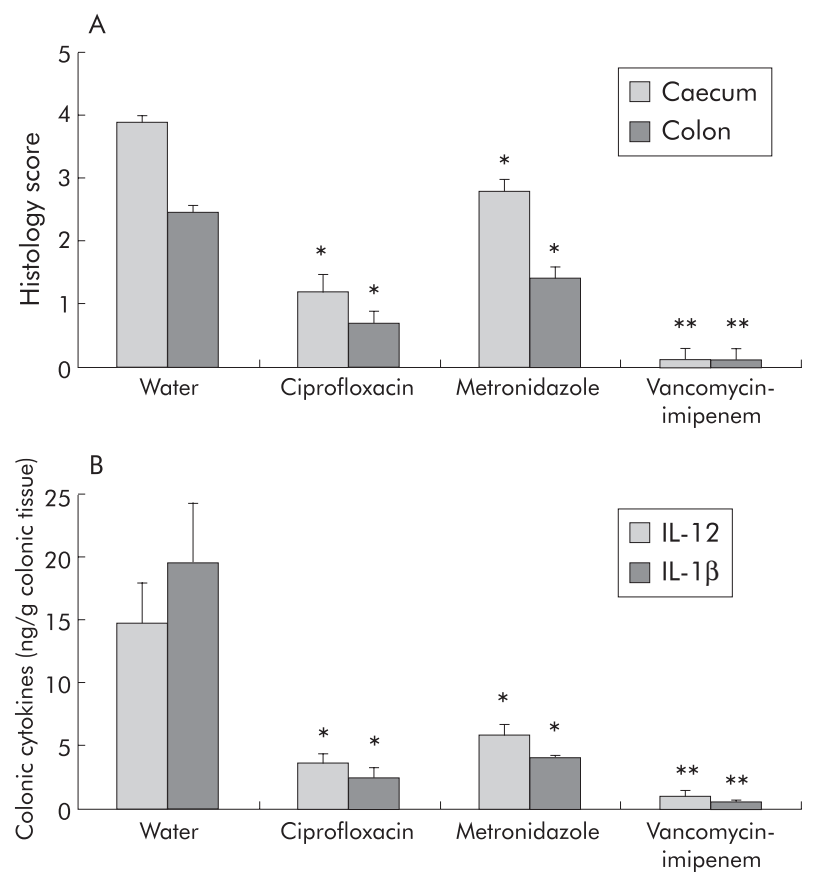

Figure 1 Prevention study. (A) Blinded total colonic inflammatory scores. (B) Spontaneous interleukin (IL)-1 $\beta$ and IL-12 production in colonic explants cultured for 18 hours. Histological scores (0-4) (A) and colonic cytokine secretion (ng/g colonic tissue) (B) were evaluated in gnotobiotic IL-10 $10^{-/-}$mice four weeks after specific pathogen free colonisation, who were simultaneously treated with water, oral ciprofloxacin, metronidazole, or vancomycin-imipenem $150 \mathrm{mg} / \mathrm{kg}$ body weight/day). Each group consisted of 4-5 mice. Values are mean (SEM). ${ }^{*} p<0.05,{ }^{* *} p<0.01$ versus untreated controls.

given antibiotics at the time of colonisation with SPF faecal bacteria.

\section{Histology scores}

Figure IA shows that vancomycin-imipenem was most effective in preventing both caecal $(0.1 \quad(0.2) \quad v 4.0(0.2)$ water; $\mathrm{p}<0.01)$ and colonic inflammation $(0.1 \quad(0.2) \vee 2.9$ (0.2) water; $p<0.01)$. Ciprofloxacin and metronidazole partially prevented caecal $(1.2(0.3)$ ciprofloxacin and 2.8 (0.4) metronidazole $v 4.0(0.2)$ water; $\mathrm{p}<0.05$ for both) and colonic $(0.7(0.2)$ ciprofloxacin, $1.2(0.2)$ metronidazole $v 2.9$ (0.2) water; $\mathrm{p}<0.05$ for both) inflammation.

\section{Colonic cytokine production}

All antibiotics significantly decreased IL- $1 \beta$ production by colonic explant cultures: ciprofloxacin $(2.4(0.8) \mathrm{ng} / \mathrm{g}$ tissue; $\mathrm{p}<0.05$ ), metronidazole (4.0 (0.1) ng/g tissue; $\mathrm{p}<0.05$ ), as well as vancomycin-imipenem preventive therapy $(0.4$ (0.1) ng/g tissue; $\mathrm{p}<0.01$ ) compared with the water control group (19.6 (4.6) ng/g tissue) (fig 1B). Colonic IL-12 production followed the same trend as IL-1 $\beta$ and was significantly decreased by ciprofloxacin $(3.5(0.8) \mathrm{ng} / \mathrm{g}$ tissue; $\mathrm{p}<0.05$ ), metronidazole (5.8 (0.9) ng/g tissue; $\mathrm{p}<0.05$ ), and vancomycin-imipenem treatment $\left(\begin{array}{ll}1.0 & (0.2) \mathrm{ng} / \mathrm{g} \text { tissue; }\end{array}\right.$ $\mathrm{p}<0.01)$ compared with the water control group (14.7 (3.2) $\mathrm{ng} / \mathrm{g}$ tissue) (fig $\mathrm{lB}$ ).

\section{Treatment study}

We then determined whether these antibiotics could reverse established colitis. We have previously reported that GF IL- $10^{-1-}$ mice colonised with SPF bacteria develop significant mucosal inflammation by one week of bacterial colonisation, ${ }^{15}$ especially prominent in the caecum (caecal histological score $2.5(0.4)$ in SPF $v 0.2(0.2)$ in GF $\mathrm{IL}-10^{-/-}$mice $(\mathrm{p}<0.001)$; colonic score $1.9(0.3))$ which progressively increased to submucosal involvement by three weeks (caecal histological score $2.9(0.6)$; colon $1.8(0.3))$. Thus GF IL- $10^{-/-}$ mice two weeks after colonisation with SPF bacteria have well established colitis.

\section{Histology scores}

Six weeks after SPF colonisation, and four weeks after antibiotic treatment was started, vancomycin-imipenem was most effective in reversing both established caecal $(0.2(0.2) v$ $3.9(0.2)$ water; $\mathrm{p}<0.01)$ and colonic $(0.2(0.2) \vee 3.0(0.3)$; $\mathrm{p}<0.01$ ) inflammation (fig 2A). Ciprofloxacin partially decreased caecal (1.4 (0.5) v 3.9 (0.2) water; p<0.05) but not colonic (2.3 (0.3); NS) inflammation whereas metronidazole had no effect on caecal inflammation (3.4 (0.5); NS) but did partially treat colonic inflammation (1.0 (0.3) metronidazole $v 3.0(0.3)$ water control; $\mathrm{p}<0.05)$.

\section{Colonic cytokine production}

IL-1 $\beta$ production by colonic explants was significantly decreased by metronidazole (1.5 (0.3) ng/g tissue; $\mathrm{p}<0.01$ ) and vancomycin-imipenem $(0.8(0.4) \mathrm{ng} / \mathrm{g}$ tissue; $\mathrm{p}<0.01)$ compared with the control group (18.0 (5.3) ng/g tissue) (fig 2B). However, ciprofloxacin failed to significantly reduce colonic IL-1 $\beta$ production (12.2 (4.4) ng/g tissue; NS). IL-12 production by colonic explants was decreased by metronidazole $(6.7$ (1.2) ng/g tissue; $\mathrm{p}<0.05)$ and vancomycin-imipenem (3.3 (0.3) ng/g tissue; $\mathrm{p}<0.05)$ compared with water control mice (21.4 (1.5) ng/g tissue) (fig 2B). Ciprofloxacin did not have any effect on colonic IL-12 production (21.5
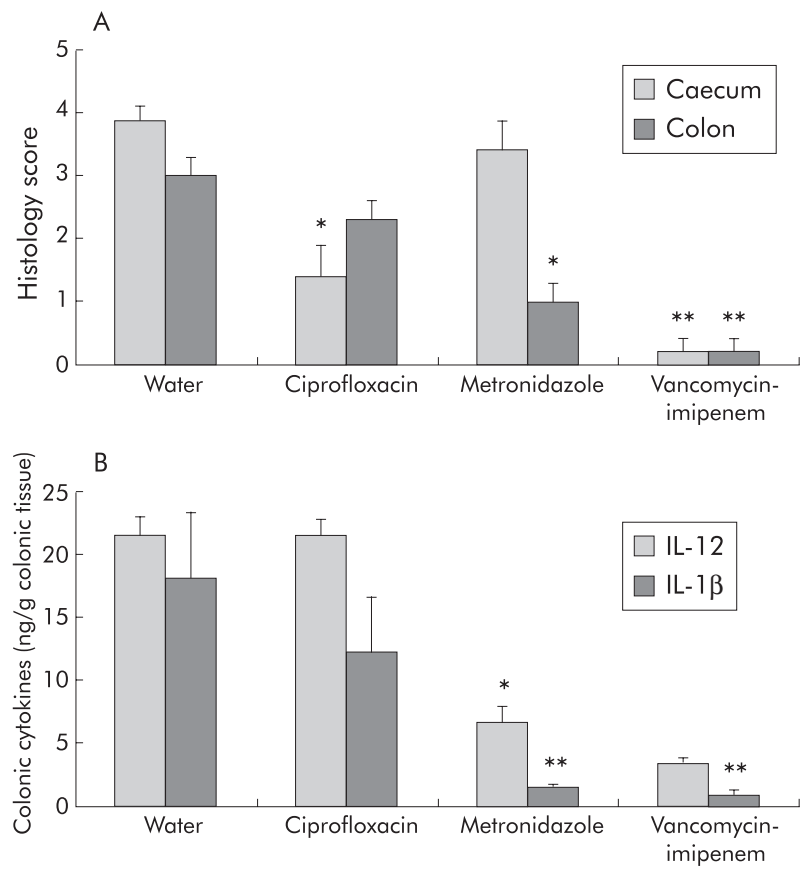

Figure 2 Treatment study. (A) Blinded total colonic inflammatory scores. (B) Spontaneous interleukin (IL)- $1 \beta$ and IL-12 production in colonic explants cultured for 18 hours. Histological scores (0-4) and colonic cytokine secretion ( $\mathrm{ng} / \mathrm{g}$ colonic tissue) were evaluated in gnotobiotic IL-10 $10^{-/-}$mice six weeks after specific pathogen free (SPF) colonisation. Two weeks after SPF colonisation resulting in established colitis, antibiotic treatment $(50 \mathrm{mg} / \mathrm{kg}$ body weight/day) was started with water, oral ciprofloxacin, metronidazole, or vancomycin-imipenem. Each group consisted of $4-5$ mice. Values are mean (SEM). ${ }^{*} p<0.05$, ${ }^{* *} \mathrm{p}<0.01$ versus untreated controls. 
(1.3) ng/g tissue; NS) compared with the water control group.

\section{Quantitative bacteriology of caecal and colonic contents}

Direct microscopic bacterial counts of caecal contents were 1-2 log lower in the vancomycin-imipenem group compared with water controls and was unchanged from controls in ciprofloxacin or metronidazole treated mice (table 1). Although DAPI stained cell counting only showed a fivefold reduction in total microbial cells in vancomycin-imipenem treated mice versus other groups, most of these were identified as yeasts (table 2). The number of caecal total aerobic bacteria was significantly lower in ciprofloxacin treated mice versus other groups. The amounts of $E$ coli and enterococci species were significantly decreased by ciprofloxacin and vancomycin-imipenem treatment (table 1). Metronidazole treatment significantly increased amounts of luminal $E$ coli. These results were confirmed by FISH of the same caecal contents, which also identified that enterococci spp were mainly E faecalis (table 2 ). Total anaerobic bacterial amounts were significantly decreased by metronidazole as well as vancomycin-imipenem treatment, with far greater effects seen with the combination treatment, as shown in table 1. FISH detected large populations of lactobacilli in control mice, which were significantly decreased by ciprofloxacin and eliminated by vancomycin-imipenem treatment. Both metronidazole and vancomycin-imipenem decreased Bacteroides spp amounts below detectable levels, which was confirmed by FISH (tables 1, 2). No significant differences were observed between quantitative bacteriological results from caecal versus colonic bacterial contents (data not shown).

We then investigated statistical correlations between histological inflammation and bacterial counts using the Spearman correlation coefficient as a non-parametric measure of the correlation of ranks. The correlation of ranks instead of the correlation of the raw data was computed because the data were skewed and the assumptions required to do hypothesis testing on the parametric correlation coefficient were not satisfied. We merged all treatment groups to see whether we could show a threshold for either total microbes or any of the species cultured, related to perpetuation of colitis. Direct microscopic bacterial counts strongly correlated with caecal inflammation $(r=0.77$, $\mathrm{p}=0.0002$ ) but to a lesser extent with colonic inflammation $(r=0.53, \mathrm{p}=0.02)$. Total aerobic counts did not correlate with overall disease, and in fact were negatively correlated with colonic inflammation $(r=-0.73, \mathrm{p}=0.0006)$. Caecal but not colonic inflammation correlated with $E$ coli concentrations $(r=0.76, \mathrm{p}=0.0003)$ and with $E$ faecalis concentrations $(r=0.70, \mathrm{p}=0.001)$. In contrast, colonic but not caecal inflammation strongly correlated with total anaerobes $(r=0.79, \mathrm{p}=0.0001)$ and Bacteroides spp $(r=0.89$, $\mathrm{p}=0.0001)$

\section{DISCUSSION}

Bacteria and their products play a crucial role in the pathogenesis of chronic intestinal inflammation in animal models and human IBD, ${ }^{12}$ providing therapeutic potential for antibiotics to manipulate the intestinal flora in order to influence the onset and course of disease. GF IL- $10^{-1-}$ mice do not have colitis in the absence of intestinal bacteria, but we showed previously that they rapidly develop a THI mediated transmural acute and chronic inflammation within one week after colonisation with SPF bacteria. ${ }^{15}$ Therefore, following identical protocols, ${ }^{15}$ this model provided us the opportunity to investigate established colitis two weeks after SPF colonisation. In our studies, 4-6 weeks after SPF bacteria, the caecum was consistently more affected than the colon in IL- $10^{-/-}$mice.

We first showed that the broad spectrum combination vancomycin-imipenem almost completely prevented and treated both caecal and colonic inflammation, in agreement with previous reports by several authors in various models. A combination of metronidazole and neomycin prevented and treated colitis in IL- $10^{-1-}$ mice. ${ }^{14}$ Vancomycin-imipenem prevented and treated colitis in HLA-B27 rats, DSS induced colitis in mice, ${ }^{13}$ as well as trinitrobenzene sulphonic acid induced experimental colitis in rats. ${ }^{22}$ Although the combination of ciprofloxacin and metronidazole prevented and treated inflammation in the SAMPI/Yit spontaneous ileitis model, ${ }^{23}$ it improved acute but not chronic DSS induced colitis in mice. ${ }^{24}$ In human studies the combination of ciprofloxacin and metronidazole was reported to be effective in treating refractory pouchitis ${ }^{25}$ as well as active Crohn's disease. ${ }^{26} 27$

We also showed that narrow spectrum antibiotics such as ciprofloxacin or metronidazole prevented caecal and colonic inflammation in gnotobiotic IL- $10^{-1-}$ mice after SPF colonisation, but only selectively reversed established colitis. The higher efficacy of narrow spectrum antibiotics for prevention rather than treatment of colitis is in agreement with previous studies. For example, ciprofloxacin prevented induction of colitis in IL- $10^{-/-}$mice born under SPF conditions but showed only minor effects in established colitis. ${ }^{14}$ Metronidazole prevented DSS induced colitis in mice but this antibiotic had no effect after the onset of colitis. ${ }^{24}$ In HLA-B27 TG rats and DSS treated mice, oral administration of either ciprofloxacin or metronidazole prevented colitis but was less effective in treating established inflammation. ${ }^{13}$ The greater efficacy of narrow spectrum antibiotics for preventing colitis may be explained by the different roles for various endogenous bacterial species in the different phases of the inflammatory process. As proposed by Rath et al, some bacterial species might initiate inflammation while others, perhaps including a larger spectrum of intestinal bacteria, perpetuate disease. ${ }^{13}$ Therefore, it is easier to prevent onset of colonic inflammation than to treat established disease. These findings are in agreement with the ability of recombinant IL-10 to prevent but not treat experimental

Table 1 Quantitative bacteriology of caecal content by bacterial cultures

\begin{tabular}{lllcccc}
\hline Treatment & $\begin{array}{l}\text { Direct microscopic bacterial } \\
\text { counts }\left(\times 10^{8}\right)\end{array}$ & $\begin{array}{l}\text { Total aerobes } \\
\left(\times 10^{7}\right)\end{array}$ & $\boldsymbol{E}$ coli $\left(\times 10^{7}\right)$ & $\begin{array}{l}\text { Enterococci } \\
\left(\times 10^{7}\right)\end{array}$ & $\begin{array}{l}\text { Total anaerobes } \\
\left(\times 10^{8}\right)\end{array}$ & $\begin{array}{l}\text { Bacteroides } \\
\text { spp }\left(\times 10^{7}\right)\end{array}$ \\
\hline Water & $38(12)$ & $5(2)$ & $7(3)$ & $48(20)$ & $86(30)$ & $32(8)$ \\
MNZ & $43(7)$ & $20(10)$ & $84(13)^{* *}$ & $57(30)$ & $4.8(5)^{*}$ & $<0.001^{* *}$ \\
Cipro & $24(6)$ & $<0.001^{* *}$ & $<0.001^{* *}$ & $0.2(0.1)^{* *}$ & $96(50)$ & $28(5)$ \\
V+1 & $1(0.1)^{* *}$ & $21(10)$ & $<0.001^{* *}$ & $<0.001^{* *}$ & $<0.001^{* *}$ & $<0.001^{* *}$ \\
\hline
\end{tabular}

Direct microscopic bacterial counts and caecal concentrations of aerobic bacteria, Escherichia coli, enterococci, as well as total anaerobic bacteria, including

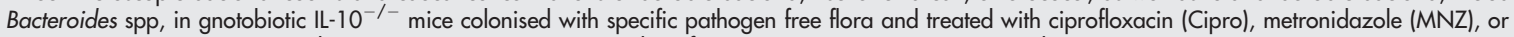
vancomycin-imipenem $(\mathrm{V}+\mathrm{I})$. Values are given as mean (SEM) colony forming units (CFU) per gram caecal contents. ${ }^{*} p<0.05,{ }^{* *} p<0.01$ versus water controls. 
Table 2 Quantitative bacteriology of caecal content by fluorescent in situ hybridisation

\begin{tabular}{llclll}
\hline Treatment & $\begin{array}{l}\text { Total bacterial } \\
\text { count }\left(10^{8}\right)\end{array}$ & E coli $\left(10^{7}\right)$ & $\begin{array}{l}E \text { faecalis } \\
\left(10^{7}\right)\end{array}$ & $\begin{array}{l}\text { Bacteroides } \\
\text { spp }\left(10^{7}\right)\end{array}$ & $\begin{array}{l}\text { Lactobacilli } \\
\text { spp }\left(10^{7}\right)\end{array}$ \\
\hline Water & $86(21)$ & $6(2)$ & $40(38)$ & $114(39)$ & $141(40)$ \\
MNZ & $85(9)$ & $171(47)^{* *}$ & $78(40)$ & $<1^{* *}$ & $247(48)$ \\
Cipro & $31(7)$ & $<1^{* *}$ & $<1^{* *}$ & $61(12)$ & $11(5)^{* *}$ \\
V+1 & $18(1)^{* *}$ & $<1^{* *}$ & $<1^{* *}$ & $<1^{* *}$ & $<1^{* *}$ \\
\hline
\end{tabular}

Caecal luminal concentrations of Escherichia coli, enterococci, Bacteroides spp, and lactobacilli spp in gnotobiotic IL-10-1- mice colonised with specific pathogen free flora and treated with ciprofloxacin (Cipro), metronidazole (MNZ), or vancomycin-imipenem (V+l). Values are given as mean (SEM) per gram of caecal content, measured by fluorescent in situ hybridisation using probes specific for $16 \mathrm{~S}$ ribosomal RNA of $E$ coli, Enterococcus faecalis, Bacteroides spp, and lactobacilli spp.

$<1$, below detection limit of $10^{7}$ bacteria/g content. ${ }^{* *} p<0.01$ versus water controls.

chronic granulomatous inflammation induced by bacterial cell wall polymers in rats. ${ }^{28}$ This might also explain the relative lack of efficacy by metronidazole and ciprofloxacin in the treatment of ileal Crohn's disease ${ }^{29}$ whereas metronidazole or ornidazole could prevent recurrence of Crohn's disease in the neoterminal ileum after ileal resection and primary ileocolonic anastomosis. ${ }^{30} 31$

A unique feature of our study is the observation that narrow spectrum antibiotics showed regional differences in treating established colitis in IL-10 $0^{-1-}$ mice. Ciprofloxacin was most beneficial in the caecum but did not treat colonic inflammation whereas metronidazole was more effective in the colon. On the other hand, the broad spectrum antibiotics vancomycin-imipenem were superior to ciprofloxacin or metronidazole alone and successfully treated both intestinal regions. Regional specificity of antibiotics is seen in human Crohn's disease in which metronidazole, either alone or in combination with ciprofloxacin, is more effective in colonic versus ileal Crohn's disease, ${ }^{27}{ }^{29}{ }^{32}$ although in a small study ciprofloxacin did treat Crohn's ileitis. ${ }^{33}$ In two other studies, the efficacy of ciprofloxacin in relation to disease localisation was not mentioned..$^{34}$ In our study, cytokine production by colonic explants, normalised for tissue weight, was significantly reduced by metronidazole but not by ciprofloxacin, demonstrating the specificity of ciprofloxacin for the caecal region rather than the colon.

Treatment with vancomycin-imipenem correlated with a 1-2 log decrease in total luminal bacteria while other treatments did not significantly decrease total luminal bacterial concentrations. Similar effects on total caecal bacterial load by this antibiotic combination have been reported in HLA-B27 TG rats $^{13}$ as well as by metronidazole plus ciprofloxacin treatment in the SAMP/Yit mouse model, ${ }^{23}$ most likely due to emergence of resistant bacterial species. Our results confirm the importance of luminal antigenic bacterial load in the perpetuation of chronic colitis as the broad spectrum antibiotic combination almost totally eliminated disease. When all treatment groups were merged, there was a significant correlation between direct microscopic bacterial counts and histology scores in both the caecum and colon. However, reduction of bacterial load is not the only mechanism involved in response to treatment because (1) narrow spectrum antibiotics have selective therapeutic effects in different large intestinal regions, despite the lack of effect on direct microscopic bacterial counts in IL- $10^{-/-}$mice, (2) vancomycin-imipenem was more effective than ciprofloxacin in reducing caecal inflammation, but did not decrease the total aerobic count, and (3) decreased luminal $E$ coli and $E$ faecalis concentrations, but not total aerobic counts, correlated with reduced caecal inflammation. Therefore, our results suggest that not only reduced bacterial load but also specific subsets of aerobic bacteria such as $E$ coli, may preferentially perpetuate caecal inflammation, while anaero- bic bacteria, including Bacteroides, cause colitis. This hypothesis is consistent with the selective effects of ciprofloxacin in the caecum and metronidazole in the colon. Ciprofloxacin is most effective against enteric aerobic Gram negative organisms, and in our study it significantly reduced total caecal and colonic aerobic bacteria, with undetectable $E$ coli and a significantly reduced amount of luminal enterococci spp. Interestingly, in preliminary studies, $\mathrm{IL}-10^{-/-}$mice monoassociated with $E$ coli preferentially develop caecal inflammation. ${ }^{36} E$ coli could therefore play a role in the (induction and) perpetuation of caecal inflammation in SPF IL- $10^{--/}$mice. Despite elevated amounts of caecal $E$ coli in HLA-B27 TG rats with severe chronic colitis, ${ }^{37}$ monoassociation of these rats with $E$ coli did not induce colitis in these rats ${ }^{38}$ indicating that the ability of $E$ coli to induce and perpetuate chronic colitis is host dependent. The potential role of $E$ coli in chronic intestinal inflammation was further emphasised by the observation that ileal mucosa from Crohn's patients with postoperative recurrence contained more enteroadherent/invasive $E$ coli strains than healthy controls. ${ }^{39}$ In addition, IBD patients have increased serum and mucosal antibody responses to $E$ coli. ${ }^{40}$ Monoassociation of IL- $10^{-1-}$ mice with $E$ faecalis induces a distal colitis with slow onset of disease, starting at 12 weeks of colonisation..$^{3643}$ Although ciprofloxacin reduced caecal inflammation and luminal concentrations of $E$ faecalis in our study, the regional localisation (distal colon $v$ caecum) and the slow onset of disease in monoassociated IL- $10^{-/-}$mice make it unlikely that $E$ faecalis plays an important role in caecal inflammation. Additionally, it also appears unlikely that $E$ faecalis perpetuates established distal colitis in IL-10 $0^{-1-}$ mice colonised with SPF bacteria for 4-6 weeks as metronidazole, which selectively decreased colonic inflammation, had no effect on $E$ faecalis concentrations.

Metronidazole is selectively active against anaerobic bacteria, including colonic Gram negative Bacteroides spp. ${ }^{44}$ Metronidazole effectively treated colonic inflammation in our IL- $10^{-/-}$mice, significantly reduced luminal anaerobic bacteria, and eliminated Bacteroides spp, in both the caecum and colon, suggesting that differences in local luminal concentrations of these organisms could not explain the regional variation in colonic inflammation. Thus anaerobic bacteria appear to have little effect in caecal inflammation in this model but could play an important role in colonic inflammation. In selective colonisation studies, a cocktail of six enteric bacteria, including $B$ vulgatus, induced minimal colitis in gnotobiotic IL- $10^{-/-}$mice, ${ }^{5}$ although monoassociation with $B$ vulgatus induced colitis in carrageenan fed guinea pigs and HLA-B27 TG rats. ${ }^{38}{ }^{45}$ Additionally, Mann et al demonstrated that different Bacteroides spp show variability in pathogenic capacity, with $B$ vulgatus and Bacteroides thetaiotamicron but not Bacteroides distasonis inducing colitis in monoassociated HLA B27 TG rats. ${ }^{46}$ In our study, host 
specificity and pathogenic variability of anaerobic species might determine which organisms mediate colonic inflammation. Thus it appears likely that metronidazole eliminates anaerobic intestinal organisms other than $B$ vulgatus, which could mediate established colitis but not caecal inflammation in IL- $10^{-1-}$ mice.

Administration of several lactobacillus spp can both prevent and treat colitis in IL- $10^{-1-}$ mice. ${ }^{47}{ }^{48}$ However, our FISH analysis demonstrated that both vancomycin-imipenem and ciprofloxacin treatment eliminated lactobacilli spp whereas metronidazole did not affect endogenous luminal lactobacilli spp. Therefore, the beneficial effects of antibiotics are not mediated by increased lactobacilli spp levels.

In conclusion, selective antibiotics and broad spectrum combination antibiotics can prevent development of inflammation in both the caecum and colon of IL- $10^{-/-}$mice after colonisation with SPF bacteria. In contrast, treatment of established colitis is more selective in its regional therapeutic response. Ciprofloxacin is most effective in caecal inflammation and reduces aerobic organisms, including $E$ coli and $E$ faecalis, whereas metronidazole is preferentially active in the colon and selectively decreases anaerobic bacteria and Bacteroides spp. Vancomycin-imipenem treats both regions very effectively, reduces total luminal bacteria, and eliminates specific aerobic and anaerobic organisms. These results suggest that specific subsets of aerobic and anaerobic intestinal bacteria selectively perpetuate colitis in the caecum and colon in this experimental model of chronic intestinal inflammation.

\section{ACKNOWLEDGEMENTS}

The authors wish to thank Charlotte Walters of the ImmunoTechnology Core of the Center for Gastrointestinal Biology and Disease, University of North Carolina at Chapel Hill, Desmond McDonald of the College of Veterinary Medicine, North Carolina State University, Raleigh, and Erwin Raangs of the Department of Medical Microbiology, University of Groningen, the Netherlands, for their expert technical support. This work was supported by NIH grants KO8 DK 53773, ROI DK 53347, P30 DK 34987, and by the Crohn's and Colitis Foundation of America.

\section{Authors' affiliations}

F Hoentien, Department of Gastroenterology, Free University Amsterdam, The Netherlands, and Center for Gastrointestinal Biology and Disease, University of North Carolina, Chapel Hill, USA. C D Torrice, B A Mann, R B Sartor, L A Dieleman, Center for Gastrointestinal Biology and Disease, University of North Carolina, Chapel Hill, USA

H J M Harmsen, Department of Medical Microbiology, University of Groningen, the Netherlands

H Braat, Department of Experimental Internal Medicine, Academic Medical Centre, Amsterdam, the Netherlands

\section{REFERENCES}

1 Podolsky DK. Inflammatory bowel disease. N Engl J Med 2002;347:417-29.

2 Sartor RB. Microbial factors in the pathogenesis of Crohn's disease, ulcerative colitis, and experimental intestinal inflammation. In: Sartor RB, Sandborn WJ, eds. Kirsner's inflammatory bowel diseases, 6th ed. Philadelphia: Saunders, 2003:138-62.

3 Sartor RB. Enteric bacteria in chronic intestinal inflammation: role in pathogenesis and therapeutic targets. Gastroenterology 2003; 125:(in press).

4 Berg DJ, Davidson N, Kuhn R, et al. Enterocolitis and colon cancer in interleukin-10-deficient mice are associated with aberrant cytokine production and $\mathrm{CD} 4(+) \mathrm{TH}$-like responses. J Clin Invest 1996;98:1010-20.

5 Sellon RK, Tonkonogy S, Schultz M, et al. Normal enteric bacteria are necessary for the development of spontaneous colitis and immune system activation in IL-10 deficient mice. Infect Immun 1998;66:5224-31.

6 Kuhn R, Lohler J, Rennick D, et al. Interleukin-10-deficient mice develop chronic enterocolitis. Cell 1993;75:263-74.

7 Taurog JD, Richardson JA, Croft JT, et al. The germfree state prevents the development of gut and joint inflammatory disease in HLA-B27 transgenic rats. J Exp Med 1994; 180:2359-64.

8 Rath HC, Bender DE, Holt LC, et al. Normal bacteria stimulate colonic, gastric, and systemic inflammation in HLA-B27/ $\beta 2 \mathrm{~m}$ transgenic rats. J Clin Invest 1996:98:945-53.
9 Dianda LA, Hanby M, Wright NA, et al. T cell receptor-alpha beta-deficient mice fail to develop colitis in the absence of a microbial environment. Am J Pathol 1997;150:91-7.

10 Matsumoto S, Okabe $Y$, Setoyama H, et al. Inflammatory bowel disease-like enteritis and caecitis in a senescence accelerated mouse Pl/Yit strain. Gut 1998;43:71-8.

11 Schultz M, Tonkonogy SL, Sellon RK, et al. IL-2-deficient mice raised under germfree conditions develop delayed mild focal intestinal inflammation. Am J Physiol 1999;276:G1461-72.

12 Veltkamp C, Tonkonogy SL, de Jong YP, et al. Continuous stimulation by normal bacteria is essential for the development and perpetuation of colitis in $\mathrm{Tg} \in 26$ mice. Gastroenterology 2001;120:900-13.

13 Rath HC, Schultz M, Freitag R, et al. Different subsets of enteric bacteria induce and perpetuate experimental colitis in rats and mice. Infect Immun $2001 ; 69: 2277-85$

14 Madsen KL, Doyle JS, Tavernini MM, et al. Antibiotic therapy attenuates colitis in interleukin 10 gene-deficient mice. Gastroenterology 2000;118:1094-105.

15 Dieleman LA, Arends A, Tonkonogy SL, et al. Helicobacter hepaticus does not induce or potentiate colitis in interleukin-10-deficient mice. Infect Immun 2000;68:5107-13.

16 Clarke SJ, Stokes CR. The intestinal and serum humoral immune response to systemically and orally administered antigens in liposomes. I. The response to liposome-entrapped soluble proteins. Vet Immunol Immunopathol 1992; 32: 125-38.

17 Franks $A H$, Harmsen HJ, Raangs GC, et al. Variations of bacterial populations in human feces measured by fluorescent in situ hybridization with group-specific 16S rRNA-targeted oligonucleotide probes. Appl Environ Microbiol 1998;64:3336-45.

18 Manz WR, Amann R, Ludwig W, et al. Application of a suite of 16S rRNAspecific oligonucleotide probes designed to investigate bacteria of the phylum cytophaga-flavobacter-bacteroides in the natural environment. Microbiology 1996;142:1097-106.

19 Poulsen LK, Licht TR, Rang C, et al. Physiological state of Escherichia coli BJ4 growing in the large intestines of streptomycin-treated mice. J Bacteriol 1995; 177:5840-5.

20 Harmsen HJM, Elfferich P, Schut F, et al. A 16S rRNA-targeted probe for detection of lactobacilli and enterococci in fecal samples by fluorescent in situ hybridization. Microbiol Ecol Health Dis 1999:11:3-12.

21 Jansen GJ, Wildeboer-Veloo AC, Tonk RH, et al. Development and validation of an automated, microscopy-based method for enumeration of groups of intestinal bacteria. J Microbiol Methods 1999;37:215-21.

22 Videla S, Vilaseca J, Guarner F, et al. Role of intestinal microflora in chronic inflammation and ulceration of the rat colon. Gut 1994;35:1090-7.

23 Bamias G, Marini M, Moskaluk CA, et al. Down-regulation of intestinal lymphocyte activation and Th1 cytokine production by antibiotic therapy in a murine model of Crohn's disease. J Immunol 2002;169:5308-14.

24 Hans W, Scholmerich J, Gross V, et al. The role of the resident intestinal flora in acute and chronic dextran sulfate sodium-induced colitis in mice. Eur J Gastroenterol Hepatol 2000;12:267-73.

25 Mimura T, Rizzello F, Helwig U, et al. Four-week open-label trial of metronidazole and ciprofloxacin for the treatment of recurrent or refractory pouchitis. Aliment Pharmacol Ther 2002;16:909-17.

26 Prantera C, Zannoni F, Scribano ML, et al. An antibiotic regimen for the treatment of active Crohn's disease: a randomized, controlled clinical trial of metronidazole plus ciprofloxacin. Am J Gastroenterol 1996:91:328-32.

27 Greenbloom SL, Steinhart AH, Greenberg GR. Combination ciprofloxacin and metronidazole for active Crohn's disease. Can J Gastroenterol 1998; 12:53-6.

28 Herfarth HH, Bocker U, Janardhanam R, et al. Subtherapeutic corticosteroids potentiate the ability of interleukin 10 to prevent chronic inflammation in rats. Gastroenterology 1998;115:856-65.

29 Steinhart AH, Feagan BG, Wong CJ, et al. Combined budesonide and antibiotic therapy for active Crohn's disease: a randomized controlled trial Gastroenterology 2002;123:33-40.

30 Rutgeerts P, Hiele M, Geboes K, et al. Controlled trial of metronidazole treatment for prevention of Crohn's recurrence after ileal resection. Gastroenterology 1995;108:1617-21.

31 Rutgeerts P, Van Assche G, D'Haens G, et al. Ornidazol for prophylaxis of postoperative Crohn's disease: Final results of a double blind placebo controlled trial. Gastroenterology 2002;122:A80.

32 Sutherland L, Singleton J, Sessions J, et al. Double-blind, placebo-controlled trial of metronidazole in Crohn's disease. Gut 1991;32:1071-5.

33 Peppercorn MA. Is there a role for antibiotics as primary therapy in Crohn's ileitis? J Clin Gastroenterol 1993;17:235-7.

34 Colombel JF, Lemann M, Cassagnou M, et al. A controlled trial comparing ciprofloxacin with mesalazine for the treatment of active Crohn's disease. Groupe d'Etudes Therapeutiques des Affections Inflammatoires Digestives (GETAID). Am J Gastroenterol 1999;94:674-8.

35 Arnold GL, Beaves MR, Pryjdun VO, et al. Preliminary study of ciprofloxacin in active Crohn's disease. Inflamm Bowel Dis 2002:8:10-15.

36 Kim SC, Tonkonogy SL, Albright CA, et al. Regional and host specificity of colitis in mice monoassociated with different non-pathogenic bacteria. Gastroenterology 2003;124:A485.

37 Onderdonk $A B$, Richardson JA, Hammer RE, et al. Correlation of cecal microflora of HLA-B27 transgenic rats with inflammatory bowel disease. Infect Immun 1998;66:6022-3.

38 Rath HC, Wilson KH, Sartor RB. Differential induction of colitis and gastritis in HLA-B27 transgenic rats selectively colonized with Bacteroides vulgatus or Escherichia coli. Infect Immun 1999:67:2969-74. 
39 Darfeuille-Michaud A, Neut C, Barnich N et al. Presence of adherent Escherichia coli strains in ileal mucosa of patients with Crohn's disease. Gastroenterology 1998;115:1405-13.

40 Tabaqchali S, O'Donoghue DP, Bettelheim KA. Escherichia coli antibodies in patients with inflammatory bowel disease. Gut 1978:19:108-13.

41 Macpherson A, Khoo UY, Forgacs I, et al. Mucosal antibodies in inflammatory bowel disease are directed against intestinal bacteria. Gut 1996;38:365-75.

42 Kim SC, Tonkonogy SL, Albright CA, et al. Enterococcus faecalis monoassociated IL-10 deficient mice develop colitis and selective bacterial species-specific immune responses. Gastroenterology 2001; 120:A441.

43 Balish E, Warner T. Enterococcus faecalis induces inflammatory bowel disease in interleukin-10 knockout mice. Am J Pathol 2002;160:2253-7.
44 Krook A Jarnerot G Danielsson D. Clinical effect of metronidazole and sulfasalazine on Crohn's disease in relation to changes in the fecal flora. Scand J Gastroenterol 1981;16:569-75.

45 Onderdonk AB, Franklin ML, Cisneros RL. Production of experimental ulcerative colitis in gnotobiotic guinea pigs with simplified microflora. Infect Immun 1981;32:225-31.

46 Mann BA, Kim SC, Sartor RB. Selective induction of experimental colitis by monoassociation of HLA-B27 transgenic rats with various enteric Bacteroides species. Gastroenterology 2003;124:A322.

17 Madsen KL, Doyle JS, Jewell LD, et al. Lactobacillus species prevents colitis in interleukin-10 gene deficient mice. Gastroenterology 1999;116:1107-14.

48 Schultz M, Veltkamp C, Dieleman L, et al. Lactobacillus plantarum 299v in the treatment and prevention of spontaneous colitis in interleukin-10 deficient mice. Inflamm Bowel Dis 2002;8:71-80.

\section{GI SNAPSHOT}

\section{Fever, night sweats, and a hepatic mass}

\section{Question}

A 41 year old Hispanic man with no significant medical history presented with a two month history of fever, chills, and night sweats. He denied nausea, vomiting, diarrhoea, weight loss, cough, and dysuria. On examination he was in no acute distress, with a temperature of $38.2^{\circ} \mathrm{C}(100.8 \mathrm{~F})$, and normal vital signs. He had mild right upper quadrant tenderness and an enlarged liver. Initial laboratory data were remarkable except for microcytic anaemia and an erythrocyte sedimentation rate of 95 . The patient was admitted to the hospital to investigate his recurring fevers. Although he had temperatures as high as $40.3^{\circ} \mathrm{C}(104.5 \mathrm{~F})$, his infectious workup was negative. Bacterial cultures of his blood, urine, and sputum were negative, as were fungal cultures. Serology for entamoeba, echinococcus, and human immunodeficiency virus were also negative. In the course of his workup he had a computed tomography scan of the abdomen. How can this image explain the clinical scenario?

See page 1773 for answer

J M Levsky

D T Farkas

A Narula

Department of Surgery, Jacobi Medical Center and Albert Einstein College of Medicine, Bronx, NY, USA; jlevsky@aecom.yu.edu

Correspondence to: Dr J M Levsky; ¡levsky@aecom.yu.edu

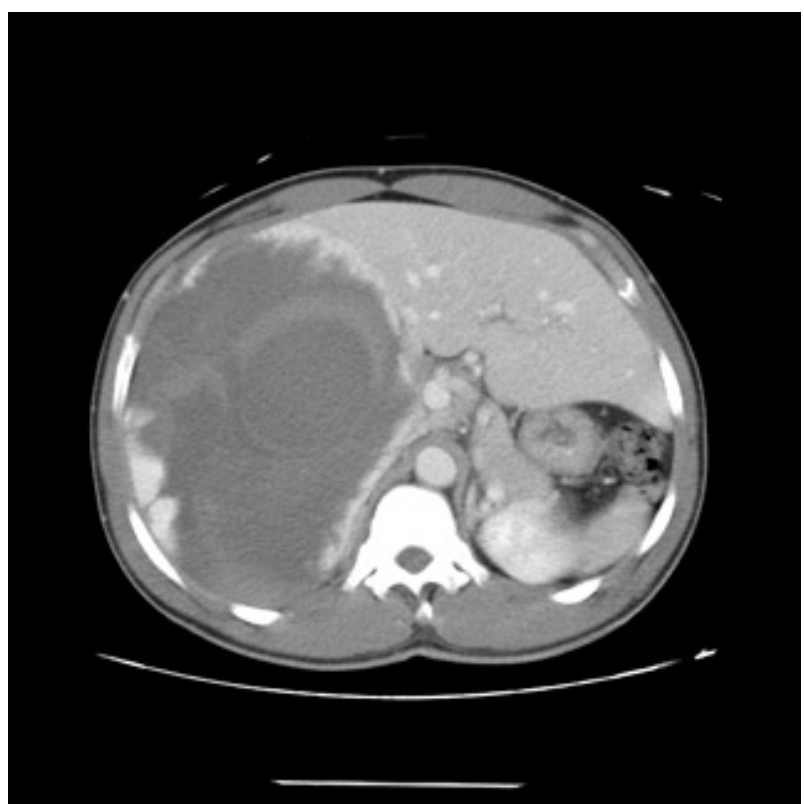

Figure 1 Contrast enhanced computed tomography image of the liver. 